Review Article

\title{
Therapeutic Strategies for Oxidative Stress-Related Cardiovascular Diseases: Removal of Excess Reactive Oxygen Species in Adult Stem Cells
}

\author{
Hyunyun Kim, Jisoo Yun, and Sang-Mo Kwon \\ Laboratory for Vascular Medicine and Stem Cell Biology, Convergence Stem Cell Research Center, Medical Research Institute, \\ Pusan National University School of Medicine, Yangsan 50612, Republic of Korea
}

Correspondence should be addressed to Sang-Mo Kwon; smkwon323@hotmail.com

Received 13 June 2016; Accepted 17 August 2016

Academic Editor: Benjamin Pineda

Copyright (C) 2016 Hyunyun Kim et al. This is an open access article distributed under the Creative Commons Attribution License, which permits unrestricted use, distribution, and reproduction in any medium, provided the original work is properly cited.

\begin{abstract}
Accumulating evidence indicates that acute and chronic uncontrolled overproduction of oxidative stress-related factors including reactive oxygen species (ROS) causes cardiovascular diseases (CVDs), atherosclerosis, and diabetes. Moreover ROS mediate various signaling pathways underlying vascular inflammation in ischemic tissues. With respect to stem cell-based therapy, several studies clearly indicate that modulating antioxidant production at cellular levels enhances stem/progenitor cell functionalities, including proliferation, long-term survival in ischemic tissues, and complete differentiation of transplanted cells into mature vascular cells. Recently emerging therapeutic strategies involving adult stem cells, including endothelial progenitor cells (EPCs), for treating ischemic CVDs have highlighted the need to control intracellular ROS production, because it critically affects the replicative senescence of ex vivo expanded therapeutic cells. Better understanding of the complexity of cellular ROS in stem cell biology might improve cell survival in ischemic tissues and enhance the regenerative potentials of transplanted stem/progenitor cells. In this review, we will discuss the nature and sources of ROS, drug-based therapeutic strategies for scavenging ROS, and EPC based therapeutic strategies for treating oxidative stress-related CVDs. Furthermore, we will discuss whether primed EPCs pretreated with natural ROS-scavenging compounds are crucial and promising therapeutic strategies for vascular repair.
\end{abstract}

\section{Introduction}

Cardiovascular diseases (CVDs), including ischemic heart disease, stroke, and hypertensive heart diseases are the leading cause of death worldwide [1]. Multiple factors of hemodynamic conditions including shear stress, laminar flow, turbulent flow, extracellular signaling proteins, including interleukins, chemokines, and cytokines, and intracellular biochemical molecules including reactive oxygen species (ROS) affect the condition of blood vessels [2-4]. High blood pressure and inflammatory reaction induced damage of blood vessels lead to hypertension, ischemic heart disease, stroke, and so forth $[5,6]$. Several studies have focused on developing drug and stem cell-based therapeutic strategies for repairing ischemic blood vessels and for preserving a healthy and intact blood-endothelial barrier in patients with CVDs [7].

Recent studies have reported that uncontrolled overproduction of oxidative stress-related factors, including ROS, causes CVDs [8], atherosclerosis [9], and diabetes [10]. ROS, which are chemically reactive molecules, a spontaneously produced metabolic by-product in healthy cells, nicotinamide adenine dinucleotide phosphate (NADPH) oxidase, a superoxide-producing enzyme, present in vascular endothelial and adventitial cells, is involved in ROS production [11]. Pathophysiological conditions induce an imbalance between ROS (also known as oxidants) and antioxidants. Excess ROS not only affect blood vessels, but also promote the homing of endothelial progenitor cells (EPCs) into peripheral blood [12, 13]. Accumulating evidences clearly suggest that EPCs recruited to injured ischemic sites induce neovessel formation, leading to the repair of injured tissues.

EPCs were originally identified as angiogenic progenitor cells derived from the bone marrow (BM) and blood [14], as well as other organs or tissues, including cord blood, fetal liver, and skeletal muscles. Circulating EPCs mobilized in response to ischemic repair signaling may directly reach 
ischemic injury sites and proliferate and differentiate in situ into mature endothelial cells (ECs) or smooth muscle cells (SMCs) [15] or may indirectly promote the proliferation or differentiation of resident ECs, resulting in the production of multiple angiogenic cytokines at ischemic sites. Many clinical studies have also reported that EPC dysfunction is closely correlated with vascular homeostasis and various CVDs, such as myocardial infarction, stroke, and hypertension [16]. Accumulating reports recently provide stem/progenitor cellbased therapy strategies using EPCs [7]. The pivotal process of these strategies can be simply explained in multiple steps as follows. First, the process of identification of target agents including chemicals, biomolecules, and natural molecules by cell-based screening should be addressed [17]. Second, the selected target agents should be further evaluated by multiple EPC functional assays including cell proliferation, differentiation, and specific ability in vitro [18]. Third, the primed EPCs treated by target reagents should be confirmed in ischemic animal model mice by transplanting cultured cells into ischemic mouse model [19] and eventually clarified the in vivo molecular mechanism of the blood vessel repair [20]. Many studies focused on enhancing EPC functionalities by screening target intracellular signaling molecules indicate that appropriate control of intracellular antioxidant production promotes stem/progenitor cell bioactivities, including cell proliferation, differentiation of transplanted cells into mature vascular cells, and long-term cell survival in ischemic tissues in ischemic CVDs [21, 22].

In this review, we will discuss the basis and generation of ROS, its cellular signaling, current studies on drug-based therapeutics against ROS production, and cell-based therapeutics against oxidative stress-induced vascular diseases. In particular, we will discuss recent promising strategies that enhance EPC function by blocking excess ROS production, which induces blood vessels injury, to provide a novel direction for future cell-based therapies for blood vessel repair.

\section{Reactive Oxygen Species}

2.1. Basis of ROS. ROS are unavoidable by-products of aerobic metabolism [23]. ROS are generated at very high rates in organelles such as mitochondria [24], chloroplasts [25], and peroxisomes [26]. Uncommon chemical reactions during reduction and oxidation produce highly reactive oxygen compounds, including superoxide $\left(\mathrm{O}_{2}^{-}\right)$, peroxyl $\left(\mathrm{RO}_{2}^{-}\right)$, hydroxyl $\left(\mathrm{OH}^{-}\right)$, and hydroperoxyl $\left(\mathrm{HO}_{2}{ }^{-}\right)$radicals and hydrogen peroxide $\left(\mathrm{H}_{2} \mathrm{O}_{2}\right)$. ROS are harmful to cells because they damage lipids, proteins, and DNA. Lipid oxidation or peroxidation in erythrocytes causes hemolysis and carcinogenesis by affecting the oxidation process of proteins. This leads to protein fragmentation and protein-protein crosslinkages [27, 28]. In addition, increased intracellular ROS levels also induce cell damage.

2.2. Generation of ROS. In the ground state, an oxygen molecule contains two unpaired electrons. Addition of an electron fills one site of its two unpaired electrons, leading to the formation of ROS. Oxygen molecules form superoxide $\left(\mathrm{O}_{2}{ }^{-}\right)$anions [29], which are removed by superoxide dismutases (SODs). Conversion of excess superoxide anions by SODs is the key protection strategy in aerobic organisms. SODs convert superoxide anions into $\mathrm{H}_{2} \mathrm{O}_{2}$ [30]. Although $\mathrm{H}_{2} \mathrm{O}_{2}$ is not a powerful oxidizing agent, it can easily penetrate cells. $\mathrm{H}_{2} \mathrm{O}_{2}$ is removed by two enzymes, namely, catalase and peroxidase, by using different reductants such as ascorbate [31], glutathione [32], thioredoxin [33], phenolic compounds [34], and reduced nicotinamide adenine dinucleotides [35, $36]$ to produce oxygen $\left(\mathrm{O}_{2}\right)$ and two hydrogen oxide $\left(\mathrm{H}_{2} \mathrm{O}\right)$ molecules.

$\mathrm{H}_{2} \mathrm{O}_{2}$ is nontoxic to cells; however, $\mathrm{H}_{2} \mathrm{O}_{2}$ combines with transition metals such as $\mathrm{Fe}^{2+}$ [37] and $\mathrm{Cu}^{+}$[38] to form hydroxyl radicals $\left(\mathrm{HO}^{-}\right)$through fenton reaction. These hydroxyl radicals, which are highly reactive, react with almost every molecule, including DNA [39], membrane lipids [40], and carbohydrates [41], present in living cells to induce cellular dysfunction $[42,43]$.

2.3. Cellular Effects of ROS. Hydroxyl radicals react with organic compounds. These radicals bind to double bonds in heterocyclic DNA bases and attack double bonds in pyrimidines and purines at diffusion-controlled rates [44]. Electron density of target molecules in the reaction site is important for this reaction. Reaction of hydroxyl radicals with nucleotides produces various final products [45]. Substitution with mutated nucleotide bases in DNA results in base pair mismatch [46]. A single-point mutation can change the entire DNA sequence. Furthermore, effect of hydroxyl radicals on nucleotide bases induces single-and double-stranded DNA breaks [47-49].

Accumulation of DNA damage is closely associated with carcinogenesis $[50,51]$. One example is mutations in tumor suppressor genes. Tumor suppressor genes encoding p53 [52] and Ras [53] show GC to TA transversions in lung and liver cancers $[54,55]$. ROS-related signaling pathways are upregulated in various cancers [56] $\mathrm{H}_{2} \mathrm{O}_{2}$ acts as a secondary messenger and regulates protein activity [57]. Excessive activation of tyrosine phosphatases, protein tyrosine kinases, receptor kinases, and transcription factors contributes to carcinogenesis [58].

On the other hands, ROS are essential for regulating different signaling pathways [59]. ROS induce reversible posttranslational protein modifications. $\mathrm{H}_{2} \mathrm{O}_{2}$ thiol groups on cysteine residues to produce sulfenic acid (-SOH) [60]. Sulfenic acid reacts with glutathione (GSH) [61] to become glutathionylated (-SSG) [62], with amides to form a sulfenyl amide (-SN-) [63] or with nearby thiols to form disulfide bonds (-SS-) $[64,65]$. Thus, ROS modulate signaling pathways by modifying the activity of target proteins [66]. Furthermore, ROS oxidize and modify several proteins. ROS oxidize p53 [67], Jun [68], and Fos [69] to decrease their transcriptional activity. In contrast, ROS-induced oxidation of p50 [70] stimulates its transcriptional activity. Recent studies on stem cells indicate that mitochondria-targeted antioxidants or knockdown of the gene encoding complex III Rieske iron sulfur protein inhibits the differentiation of human mesenchymal stem cells (hMSCs) to adipocytes $[71,72]$. Thus, ROS are referred to as "a double-edged sword." 
Various ROS are generated through enzymatic processes by intracellular enzymes including NADPH oxidase, xanthine oxidoreductase, nitric oxide synthase (NOS), and myeloperoxidase (MPO) and through nonenzymatic processes. NADPH oxidases are a family of multiple-subunit complex enzymes that use NADPH as an electron source. Seven nox isoforms containing two membrane bound subunits gp91 and p22 and several cytoplasmic subunits (G protein, p40, p47, and p67) have been identified [73]. Xanthine oxidoreductase is composed of xanthine oxidase (XO) and xanthine dehydrogenase in the same enzyme. Only XO generates superoxide anions and $\mathrm{H}_{2} \mathrm{O}_{2}$ [74]. NOS catalyze the reaction of $\mathrm{L}$-arginine to $\mathrm{L}$-citrulline with the production of nitric oxide (NO). Different isoforms of NOS include neuronal NOS (nNOS), endothelial NOS (eNOS), and inducible NOS (iNOS) [75]. MPO belongs to a family of heme peroxidases. ROS generated by this enzyme oxidize lipids and proteins [76].

\section{Oxidative Stress-Related CVDs}

Blood vessels are widely distributed in the body; they supply nutrients for cellular needs and remove unnecessary substances. As blood vessels throughout the entire body are connected, one type of CVD can easily induce a secondary disease. Unlike other by-products, ROS damage EC and vascular SMCs [77]. For example, ROS-induced disruption of NO balance induces vasorelaxation. Moreover, ROS induce various vascular diseases because of their strong reactivity [78].

The majority of vascular diseases result from atherosclerosis [79]. ROS from SMCs and ECs move toward artery walls and react with low-density lipoprotein (LDL) [80] to produce oxidized LDL (Ox-LDL), damaging ECs [81]. OxLDL induces the expression of chemotactic factors such as macrophage colony stimulating factor [82] which activate $\mathrm{T}$ lymphocytes and monocytes that attach to ECs [83]. Moreover, growth factors secreted by ECs promote the migration of monocytes into cell adhesion sites [84]. Monocytes and lipoproteins generate ROS, which convert Ox-LDL into highly oxidized LDL [85]. Moreover, macrophages engulf this highly oxidized LDL to become foam cells [86]. With leukocyte, formed cells convert into fatty streak, where migrated SMC and fatty streak mixture become fibrous, forming fibrous cap after calcification. Excessive formation of fibrous cap results in sudden rupture, to produce thrombilike substances that close the blood vessel. These processes occur in various tissues $[87,88]$, including the heart during myocardial infarction [89], the brain during stroke [90], and the kidneys [91]. Another atherosclerosis induced disease is hypertension [92], which is also independently associated with ROS. Under normal conditions, eNOS catalyzes the production of NO from arginine [93]. Insufficient levels of tetrahydrobiopterin $\left(\mathrm{H}_{4} \mathrm{~B}\right)$ or arginine switch eNOS from a coupled state, which generate $\mathrm{NO}$, to an uncoupled state, which generate peroxides. Increased levels of vascular peroxides result in the oxidation of $\mathrm{H}_{4} \mathrm{~B}$, leading to additional NOS uncoupling. Decreased NO levels are not sufficient to relax SMCs, and this impaired relaxation of blood vessels is closely associated with hypertension [94].

\section{Therapeutic Use of Antioxidants in CVDs}

Many studies suggest that ROS are involved in the development of CVDs and play a causal role in atherothrombosis and other vascular diseases in various animal models. Some ROS inhibitors have been used for treating CVDs. The most relevant antioxidants that exert beneficial cardiovascular effects of ROS inhibitors are ascorbic acid (vitamin C), $\alpha$-tocopherol (vitamin $\mathrm{E}$ ), and $\beta$-carotene $[95,96]$. Vitamin $\mathrm{C}$ reverses endothelial dysfunction in patients with coronary artery disease [97] and attenuates abnormal vasomotor reactivity [98]. However, large-scale randomized trials evaluating vitamin $\mathrm{C}$ indicate no effect on CVDs [99]. Similarly, large randomized trials have not shown substantial cardioprotective effects of these antioxidants. A meta-analysis of randomized controlled trials failed to show the cardioprotective effects of these antioxidants and observed that these antioxidants did not reduce the number of clinical events in high-risk patients or in patients with an established disease $[100,101]$.

Vitamin $\mathrm{E}$ is one of the most effective antioxidants for preventing CVDs because of its cardioprotective effects [102]. Vitamin E has four tocopherols and four tocotrienols. Each vitamin $\mathrm{E}$ type consists of four isoforms (alpha $(\alpha)$, beta $(\beta)$, gamma $(\gamma)$, and delta $(\delta))$. Of the eight types of molecules, the activity of $\alpha$-tocopherol defines the quality of vitamin $\mathrm{E}$. Lipid-soluble antioxidant $\alpha$-tocopherol reacts with lipid radicals and protects the cell membrane. $\gamma$-Tocopherol, another form of vitamin $\mathrm{E}$, reacts with electrophilic mutagens and inhibits carcinogenesis $[103,104]$. In addition, vitamin E not only decreases the risk of coronary heart disease [105-108], but also reduces coronary artery disease and cardiovascular events.

$\beta$-Carotene, a reddish-orange pigment found in certain fruits and vegetables, is type of carotene. This phytonutrient quenches singlet oxygen with greater efficiency [109]. $\beta$ Carotene is a precursor of vitamin $\mathrm{A}$ and is converted into bioactive retinol (the bioactive form of vitamin A) which prevents lipid oxidation of cellular membranes. It has a similar effect of vitamin $\mathrm{E}$ but utilizes a different mechanism. It also protects human LDL from copper-stimulated oxidation [110]. Several epidemiological studies have shown that $\beta$-carotene levels are associated with reduced risk of CVDs and heart attacks [111, 112].

Lack of cardioprotective effects of currently used antioxidants has resulted in the development of new and more effective ROS inhibitors. Although mitochondria play a pivotal role in the pathogenesis of CVDs, no study has been conducted to determine mitochondria-targeting ROS inhibitors in patients with CVDs. Antioxidants therapy targeting ROS production by mitochondria might be more effective than conventional antioxidant therapy for treating CVDs [113].

\section{Cell-Based Therapeutic Strategies against Oxidative Stress-Related Diseases}

The BM is a reservoir of hematopoietic stem cells (HSCs) and generates various hematopoietic cells. Therefore, multiple diseases, including leukemia, lymphoma, and immune deficiency, can be treated by performing BM transplantation 
[114]. However, this therapeutic approach requires healthy donor BM-derived HSCs for regenerating functional stem cells and hematopoietic lineage cells to replace damaged tissues. In addition, BM transplantation is strictly regulated, for avoiding graft versus host disease [115]. Allogeneic adult stem cell therapy was developed in 2012 to overcome the limitations associated with BM transplantation with BMderived cells [116]. One approach is to isolate MSCs from the $\mathrm{BM}$ of adult donors and freeze these cells until further use; MSCs do not express MHC class I and rarely express MHC class II, thus allowing successful allogeneic transplantation by preventing immune rejection $[117,118]$. Recently, multiple adult stem cells including neural stem cells (NSCs), HSCs, EPCs, and MSCs were intensively studied for use in stem cellbased therapy.

5.1. Adult Stem Cell-Based Therapy against ROS. Stem cell niche is a microenvironment in which adult stem cells interact with adjacent cells. In addition to cells, stem cell niche contains cytokines, growth factors, and oxygen as other important components. Stem cells strictly preserve multiple capabilities, including self-renewal, proliferation, and lineage differentiation, by communicating with these different factors [119]. Quiescence of HSCs can be controlled using an adequate redox regulation system for ROS for maintaining the stemness of these cells. Although ROS production is unavoidable during cellular metabolism, high levels stimulate HSC differentiation, senescence, and apoptosis [120, 121]. However, ex vivo cultured EPCs maintain appropriate ROS level to promote the repair of blood vessel injury [122, 123]. Therefore, maintenance of a healthy status of adult stem/progenitor cells in the presence of ROS both in vitro and in vivo can be used as a therapeutic strategy and should be addressed in detail by studying ROS biology.

5.2. Understanding ROS Signaling for Adult Stem Cell Biology. The role of ROS in adult stem cell biology has been intensively studied using MSCs, HSCs, and NSCs because these major types of adult stem cells have similar properties. First, these stem cells prefer aerobic glycolysis to oxidative phosphorylation as an energy source. Second, these stem cells maintain low ROS levels, thus preserving sufficient glycolytic metabolites. Third, these stem cells have low ATP/cell content and maintain high oxygen consumption rate [124]. However, precise signaling cascades induced by ROS seem to be slightly different.

MSCs can be derived from diverse sources, including the adipose tissue, BM, and dental pulp and can differentiate into various cell types [125]. Although MSCs are a good candidate for promising cell-based therapy against tissue injury, they are very sensitive to oxygen concentration in ischemic tissues or in ex vivo cultures. In MSCs, mitogen-activated protein kinases (MAPKs) such as c-Jun N-terminal kinases (JNKs), p38, and extracellular signal-regulated kinases (ERKs) are activated by ROS. This results in the activation of apoptotic proteins and suppression of antiapoptotic signaling pathways [126], which is one of many reasons why most MSCs do not survive after transplantation [127]. In in vitro cultures,
ROS regulate MSC differentiation into three lineages, namely, adipocyte, osteocyte, and chondrocyte [128].

In HSCs, ROS generation is increased abnormally during hematopoietic homeostasis under pathological conditions [129]. Uncoordinated ROS production inhibits the selfrenewal and induces the senescence of HSCs, resulting in hematopoietic dysfunction [130]. To address the importance of ROS in HSCs, ataxia telangiectasia mutated (ATM), DNA mutation, and DNA damage checkpoint pathway in transgenic mice were intensively examined because ATM knockout (ATM-KO) mice with an abnormal ROS status show impaired hematopoietic function with aging $[131,132]$. Other groups have focused on the role of Foxo genes (Foxo1, Foxo2, and Foxo3) in ROS biology, because Foxo-KO mice also show hematopoietic dysfunctions similar to ATM-KO mice $[133,134]$. In these mice, low ROS levels are required for HSCs proliferation, differentiation, and mobilization [135]. Accumulating evidences have clearly shown that hematopoietic reconstitution after HSC transplantation is strictly required for ROS-dependent proliferation of HSCs [136]. High ROS levels damage HSCs and affect MAPK and mammalian target of rapamycin (mTOR) signaling because exposure of mTORdeficient HSCs to high ROS levels results in their sudden quiescence $[137,138]$.

Neuronal cells including neurons, astrocytes, microglia, and oligodendrocyte are generated from NSCs [139]. However, detailed mechanisms underlying ROS signaling pathways in NSCs are not completely understood. Neurogenic niche contains NSC and HSC [140]. These two types of adult stem cells show similar reaction to ROS, suggesting that NSC metabolism is similar to HSC. Some studies have shown that high endogenous ROS levels regulate proliferative NSC function including self-renewal and neurogenesis in PI3K/Akt-dependent manner [141].

5.3. ROS-Scavenging Chemicals in Stem Cells for Preclinical Study on CVDs. Muscle-derived stem cells preconditioned with $\mathrm{N}$-acetylcysteine (an antioxidant) show significant increase in their survival ratio in vivo in a mouse model of myocardial infarction [142]. Another interesting chemical compound trimetazidine (TMZ) showed primed BM-MSCs with TMZ. Evaluation of BM-MSC survival after $\mathrm{H}_{2} \mathrm{O}_{2}$ treatment showed that preconditioned BM-MSCs were protected from $\mathrm{H}_{2} \mathrm{O}_{2}$ induced damage in vitro, because of the upregulation of hypoxia inducible factor-lalpha (HIF-1 $\alpha$ ), survivin, pAKT, and B-cell lymphoma 2 (Bcl-2). Evaluation of TMZ-preconditioned MSC function in an in vivo rat model of myocardial infraction clearly showed that transplantation of primed BM-MSCs significantly increased recovery capacity by activating pAKT and Bcl-2 expression [143], suggesting that appropriate modulation of ROS production enhances repair capabilities of cells transplanted in ischemic tissues.

\section{Emerging Insights into Primed EPCs for Treating ROS-Related CVDs}

Cell-based therapy is a promising strategy for treating patients with ROS-related CVDs [144]. Cell-based therapy involves improvement of stem cell function, including 
proliferation, differentiation, and antisenescence, by priming the cells with known chemical reagents or natural products. During the onset of severe CVDs, blood vessels injured by ROS form ischemic tissues. Emerging priming strategies for EPC based therapy against oxidative stress have intensively focused on restoring these ischemic tissues.

6.1. Protective Role of Lisosan $G$ and Lady Joy against ROS in EPCs. Lisosan G (LG) is obtained from Triticum sativum (wheat). This grain is a dry powder and is registered with the Italian Ministry of Health as an alimentary integrator. Beans also contain large amounts of bioactive compounds [145]. Lady Joy (LJ) beans contain high levels of alphaamylase inhibitor phaseolamin and genetically lack phytohemagglutinin (lectin), a toxic constituent [146]. Lucchesi et al. evaluated LG and LJ. EPCs were exposed to oxidative stress $\left(\mathrm{H}_{2} \mathrm{O}_{2}\right)$ in the presence of LG and LJ [147]. These two compounds increase EPC viability and protect them against oxidative stress-induced damage. In addition, both LG and LJ improve the adhesion and decrease the senescence of EPCs. Furthermore, LG and LJ significantly decrease ROS generation in EPCs. To be specific, glutathione peroxidase1 and superoxide dismutase-2 (SOD-2) are stimulated under the lysate with $\mathrm{H}_{2} \mathrm{O}_{2}$. They clearly showed that LG promoted Nrf-2 translocation into the nucleus, suggesting that LG and LJ protected EPC bioactivities in the presence of ROS.

6.2. Protective Role of Salvianolic Acid B against Oxidative Stress in EPCs. Radix salvia miltiorrhiza (also known as Tanshen in China) is a useful plant in eastern Asia, because of its perennial cultivation characteristic. In traditional Chinese medicine, it is used for treating chronic renal failure and coronary heart disease [148]. Salvianolic acid is another interesting natural product. Salvianolic acid has diverse isoforms and is associated with other polyphenolic acids [149, 150]. Tang et al. examined the protective effects of salvianolic acid B (SalB) against oxidative stress in BM-EPCs [149]. SalB-treated EPCs showed significantly increased migration ability and tube formation capacity, which did not affect their proliferation. SalB prevents $\mathrm{H}_{2} \mathrm{O}_{2}$ induced endothelial dysfunction by downregulating NOX4, eNOS, and NADPH oxidase. Furthermore, SalB inhibits caspase-3 activation and decreases $\mathrm{Bax} / \mathrm{Bcl}-\mathrm{xL}$ ratio after $\mathrm{H}_{2} \mathrm{O}_{2}$ treatment. In this study, they suggested that SalB-mediated angiogenesis required the activation of $\mathrm{mTOR} / \mathrm{p} 70 \mathrm{~S} 6 \mathrm{~K} / 4 \mathrm{EBP} 1$ pathway. They also showed that SalB downregulated MKK3/6-p38 MAPK-ATF2 and ERK1/2 pathways, suggesting that SalB protected EPCs from oxidative stress-induced damage.

6.3. Repair of ROS-Induced Blood Vessel Injury Using Fucoidan-Pretreated Senescent EPCs. Fucoidan, a sulfated polysaccharide, is extracted from various species of brown algae and seaweed [151]. This natural product has antiviral [152], antitumor [153], antithrombotic [154], anti-inflammatory [155], and antioxidant [156] properties. Fucoidan has an ionic structure, because of which it interacts with various angiogenic proteins [157], including basic fibroblast growth factor, to improve the proangiogenic properties of EPCs [158]. Lee et al. investigated the effects of fucoidan-preconditioning of EPCs both in vitro and in vivo in a mouse model of ischemia [159]. Treatment of senescent EPCs with fucoidan rescued the expression of functional surface markers CD34, c-Kit, VEGFR2, and CXCR4, and stimulated their tube formation ability in vitro. Furthermore, fucoidan stimulated the expression of cell cycle associated proteins $\mathrm{Cdk} 4$, cyclin D1, Cdk2, and cyclin E and enhanced FAK, Akt, and ERK pathways in senescent EPCs. Transplantation of fucoidan-preconditioned EPCs into ischemic tissues of a murine model of hindlimb ischemia repaired damaged blood vessels and markedly improved limb salvage.

6.4. Protective Role of Oleuropein against ROS in EPCs. Oleuropein (OLP) is present in olive oil extracted from olive leaves [160] and has high antioxidant activity [161]. OLP contains three subunits, namely, a glucose molecule, elenolic acid, and hydroxytyrosol [162]. In vitro and in vivo studies indicate that OLP decreases the levels of superoxide anions and inhibits ROS production in leukocytes [163]. Choi et al. were the first to show the effect of OLP on vascular progenitor cells (VPCs) [164]. Angiotensin II significantly increases superoxide anion levels and decreases Prdx-1 and Prdx-2 levels in VPCs. OLP treatment significantly increased angiotensin II-induced decrease in Prdx-1 and Prdx-2 levels. These findings indicate that OLP decreases cellular ROS levels by regulating Prdx-1 and Prdx-2 expression and by activating ERK1/2 phosphorylation cascade, which is an upstream signal of Prdx-1 and Prdx-2. Thus, OLP stimulates the ERK1/2-Prdx pathway and reduces oxidative stress, thus enhancing Akt/eNOS signaling.

6.5. Protective Role of Tauroursodeoxycholic Acid against ROS in EPCs. Tauroursodeoxycholic acid (TUDCA) (also known as bile acid) is a taurine-conjugated ursodeoxycholic acid (UDCA). Bears contain large amount of TUDCA in their gall bladder. In Chinese medicine, ancient people used animal bile for several years. Moreover, TUDCA has been used for treating spasms and fevers. At present, TUDCA is used for treating of cholestatic liver disease [165]. TUDCA protects hepatocytes and restores glucose homeostasis by reducing ER stress. Cho et al. investigated the effect of TUDCA on blood vessel repair [166]. TUDCA treatment increases CD $34^{+} / \mathrm{Scal}^{+}$progenitor cells in mouse peripheral blood and $\mathrm{CD} 34^{+} / \mathrm{CD} 31^{+} / \mathrm{c}$-kit ${ }^{+}$progenitor cells in human peripheral blood. Moreover, TUDCA promotes the differentiation of CD $34^{+}$HSCs into EPC lineage cells through the Akt signaling pathway. Increased expression of adhesion molecules on EPCs promotes their association with human aortic ECs. TUDCA treatment of a mouse model of hindlimb ischemia increased the populations of $\mathrm{Flk}-1^{+} / \mathrm{CD} 34^{+}$and $\mathrm{Sca}-1^{+} / \mathrm{c}-$ $\mathrm{kit}^{+}$progenitor cells in vivo. Furthermore, $\mathrm{c}-\mathrm{kit}^{+}$progenitor cells from a BM-transplanted model of hindlimb ischemia migrated to ischemic areas to repair damaged blood vessels. In addition, TUDCA significantly decreased p21 and p53 expression levels, which are associated with cellular senescence, increased NO levels, and decreased ROS levels. Transplantation of TUDCA-preconditioned senescent EPCs into ischemic tissues induced blood vessel regeneration. 


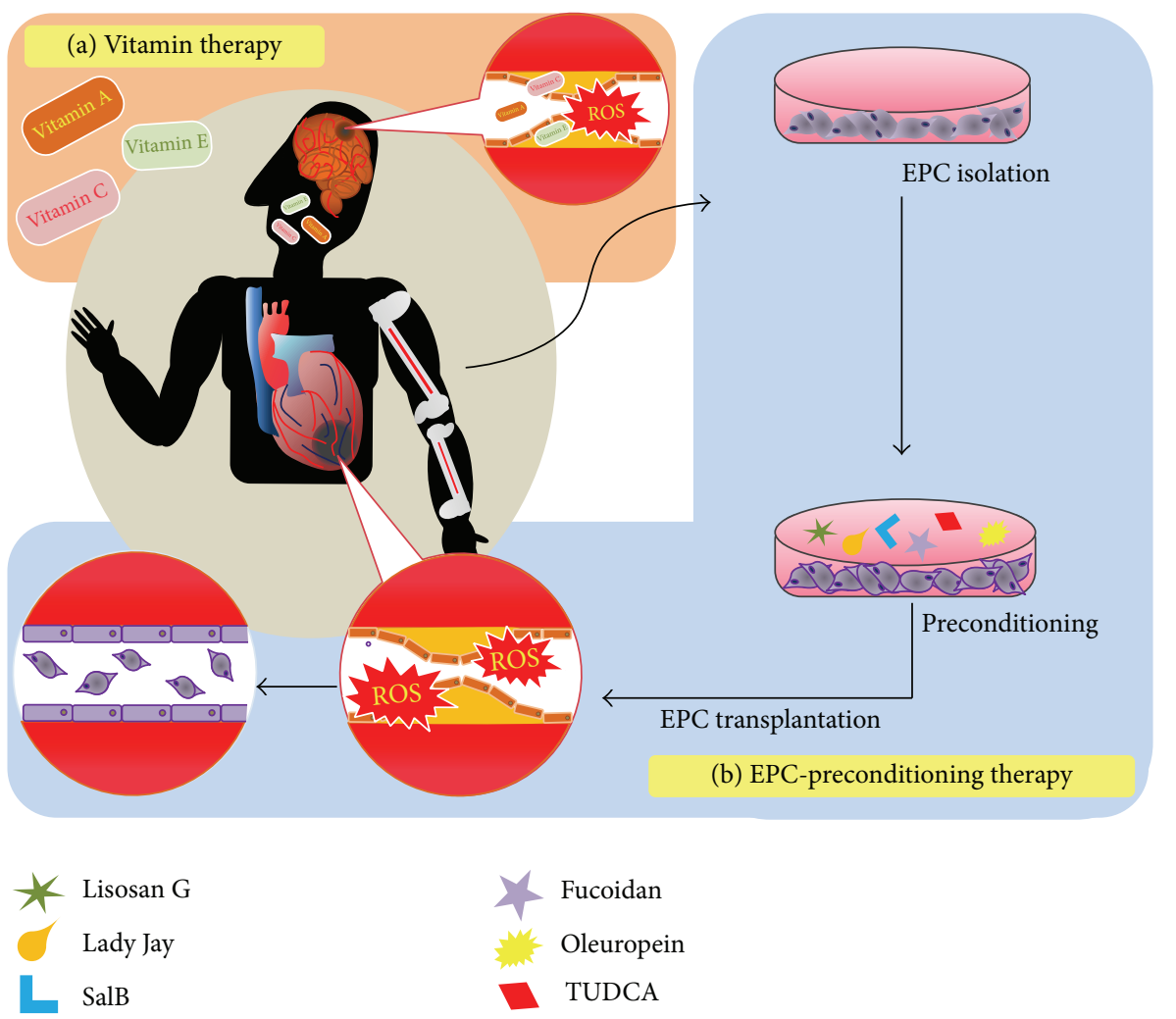

FIGURE 1: Schematic therapeutic strategies against cardiovascular diseases. (a) Vitamins therapy against ROS. (b) EPC-preconditioning therapy with antioxidant compounds. Transplanting preconditioned EPCs into ischemic tissues, such as myocardiac infarction and stroke.

\section{Conclusion}

Blood vessels are exposed to various harmful factors, including ROS, which trigger different secondary diseases. Particularly, ROS easily and highly react with other proteins in ECs and SMCs and induce multiple vascular diseases. Several research groups are attempting to overcome this pathological imbalance. A better understanding of oxidative stress signaling including ROS signaling will help in improving the bioactivities of adult stem cells, because excessive production of ROS negatively affects cellular senescence, proliferation, and differentiation. With respect to stem cell-based therapeutic strategies, several studies have clearly suggested that use of primed EPCs that block intracellular stress, including ROS, is a promising strategy for repairing oxidative stress-injured ischemic tissues. Precise understanding of drug-based therapeutics as ROS scavengers at molecular levels as well as priming of EPCs pretreated with ROS-scavenging chemicals or natural products will provide crucial and promising therapeutic approaches for treating oxidative stress-related CVDs (Figure 1).

\section{Competing Interests}

The authors declare that they do not have any conflict of interests.

\section{Authors' Contributions}

Hyunyun Kim and Jisoo Yun contributed equally to this study.

\section{Acknowledgments}

This work was supported by a grant from the National Research Foundation (NRF-2015M3A9B4051053, NRF2015R1A5A2009656, and NRF-2014R1A1A2056907), Korean Health Technology R\&D Project, Ministry of Health and Welfare (HI15C0498), funded by the Korean government, Brain Busan 21 (BB21) Program, and Brain Korea PLUS 21 (BK PLUS 21) Program.

\section{References}

[1] WHO, Medical Centre: Fact Sheets, World Health Organization, Geneva, Switzerland, 2014, http://www.who.int/mediacentre/ factsheets/fs310/en/.

[2] G. G. Rowe, J. H. Thomsen, R. R. Stenlund, D. H. McKenna, S. Sialer, and R. J. Corliss, "A study of hemodynamics and coronary blood flow in man with coronary artery disease," Circulation, vol. 39, no. 1, pp. 139-148, 1969.

[3] M. A. Creager, T. F. Lüscher, F. Cosentino, and J. A. Beckman, "Diabetes and vascular disease: pathophysiology, clinical consequences, and medical therapy: part I," Circulation, vol. 108, no. 12, pp. 1527-1532, 2003. 
[4] R. Bretón-Romero and S. Lamas, "Hydrogen peroxide signaling in vascular endothelial cells," Redox Biology, vol. 2, no. 1, pp. 529-534, 2014.

[5] G. A. Donnan, M. Fisher, M. Macleod, and S. M. Davis, "Stroke," The Lancet, vol. 371, no. 9624, pp. 1612-1623, 2008.

[6] H. Takahashi, M. Yoshika, Y. Komiyama, and M. Nishimura, "The central mechanism underlying hypertension: a review of the roles of sodium ions, epithelial sodium channels, the reninangiotensin-aldosterone system, oxidative stress and endogenous digitalis in the brain," Hypertension Research, vol. 34, no. 11, pp. 1147-1160, 2011.

[7] N. J. Leeper, A. L. Hunter, and J. P. Cooke, "Stem cell therapy for vascular regeneration: adult, embryonic, and induced pluripotent stem cells," Circulation, vol. 122, no. 5, pp. 517-526, 2010.

[8] K. Sugamura and J. F. Keaney Jr., "Reactive oxygen species in cardiovascular disease," Free Radical Biology \& Medicine, vol. 51, no. 5, pp. 978-992, 2011.

[9] G. Vogiatzi, D. Tousoulis, and C. Stefanadis, "The role of oxidative stress in atherosclerosis," Hellenic Journal of Cardiology, vol. 50, no. 5, pp. 402-409, 2009.

[10] U. Asmat, K. Abad, and K. Ismail, "Diabetes mellitus and oxidative stress-a concise review," Saudi Pharmaceutical Journal, 2015.

[11] T. Ago, T. Kitazono, H. Ooboshi et al., "Nox4 as the major catalytic component of an endothelial NAD(P)H oxidase," Circulation, vol. 109, no. 2, pp. 227-233, 2004.

[12] N. Urao, H. Inomata, M. Razvi et al., "Role of Nox2-based NADPH oxidase in bone marrow and progenitor cell function involved in neovascularization induced by hindlimb ischemia," Circulation Research, vol. 103, no. 2, pp. 212-220, 2008.

[13] C. F. H. Mueller, K. Laude, J. S. McNally, and D. G. Harrison, "Redox mechanisms in blood vessels," Arteriosclerosis, Thrombosis, and Vascular Biology, vol. 25, no. 2, pp. 274-278, 2005.

[14] S. Murasawa and T. Asahara, "Endothelial progenitor cells for vasculogenesis," Physiology, vol. 20, no. 1, pp. 36-42, 2005.

[15] T. Asahara, T. Murohara, A. Sullivan et al., "Isolation of putative progenitor endothelial cells for angiogenesis," Science, vol. 275, no. 5302, pp. 964-967, 1997.

[16] T. Watson, P. K. Y. Goon, and G. Y. H. Lip, "Endothelial progenitor cells, endothelial dysfunction, inflammation, and oxidative stress in hypertension," Antioxidants \& Redox Signaling, vol. 10, no. 6, pp. 1079-1088, 2008.

[17] J. Gao, Y. Wang, Q. Xing et al., "Identification of a natural compound by cell-based screening that enhances interferon regulatory factor-1 activity and causes tumor suppression," Molecular Cancer Therapeutics, vol. 10, no. 10, pp. 1774-1783, 2011.

[18] J. Chen, X. Xiao, S. Chen et al., "Angiotensin-converting enzyme 2 priming enhances the function of endothelial progenitor cells and their therapeutic efficacy," Hypertension, vol. 61, no. 3, pp. 681-689, 2013.

[19] C. Kalka, H. Masuda, T. Takahashi et al., "Transplantation of ex vivo expanded endothelial progenitor cells for therapeutic neovascularization," Proceedings of the National Academy of Sciences of the United States of America, vol. 97, no. 7, pp. 3422$3427,2000$.

[20] H. Iwaguro, J.-I. Yamaguchi, C. Kalka et al., "Endothelial progenitor cell vascular endothelial growth factor gene transfer for vascular regeneration," Circulation, vol. 105, no. 6, pp. 732-738, 2002.
[21] H. Fujii, S.-H. Li, P. E. Szmitko, P. W. M. Fedak, and S. Verma, "C-reactive protein alters antioxidant defenses and promotes apoptosis in endothelial progenitor cells," Arteriosclerosis, Thrombosis, and Vascular Biology, vol. 26, no. 11, pp. 2476-2482, 2006.

[22] E.-H. Yao, N. Fukuda, T. Matsumoto et al., "Losartan improves the impaired function of endothelial progenitor cells in hypertension via an antioxidant effect," Hypertension Research, vol. 30, no. 11, pp. 1119-1128, 2007.

[23] K. Apel and H. Hirt, "Reactive oxygen species: Metabolism, oxidative stress, and signal transduction," Annual Review of Plant Biology, vol. 55, pp. 373-399, 2004.

[24] M. P. Murphy, "How mitochondria produce reactive oxygen species," Biochemical Journal, vol. 417, no. 1, pp. 1-13, 2009.

[25] K. Asada, "Production and scavenging of reactive oxygen species in chloroplasts and their functions," Plant Physiology, vol. 141, no. 2, pp. 391-396, 2006.

[26] M. Schrader and H. D. Fahimi, "Peroxisomes and oxidative stress," Biochimica et Biophysica Acta (BBA)-Molecular Cell Research, vol. 1763, no. 12, pp. 1755-1766, 2006.

[27] S. V. Singh and Q. Rahman, "Interrelationship between hemolysis and lipid peroxidation of human erythrocytes induced by silicic acid and silicate dusts," Journal of Applied Toxicology, vol. 7, no. 2, pp. 91-96, 1987.

[28] C. Coşkun, A. Kural, Y. Döventaş et al., "Hemodialysis and protein oxidation products," Annals of the New York Academy of Sciences, vol. 1100, pp. 404-408, 2007.

[29] I. Fridovich, “The biology of oxygen radicals," Science, vol. 201, no. 4359, pp. 875-880, 1978.

[30] J. M. McCord and I. Fridovich, "Superoxide dismutase," Journal of Biological Chemistry, vol. 244, no. 22, pp. 6049-6055, 1969.

[31] E. L. Raven, "Peroxidase-catalyzed oxidation of ascorbate structural, spectroscopic and mechanistic correlations in ascorbate peroxidase," in Enzyme-Catalyzed Electron and Radical Transfer: Subcellular Biochemistry, vol. 35 of Subcellular Biochemistry, chapter 10, pp. 317-349, Springer, Berlin, Germany, 2000.

[32] K. P. Bhabak and G. Mugesh, "Functional mimics of glutathione peroxidase: bioinspired synthetic antioxidants," Accounts of Chemical Research, vol. 43, no. 11, pp. 1408-1419, 2010.

[33] J. Nordberg and E. S. J. Arnér, "Reactive oxygen species, antioxidants, and the mammalian thioredoxin system," Free Radical Biology \& Medicine, vol. 31, no. 11, pp. 1287-1312, 2001.

[34] A. Michalak, "Phenolic compounds and their antioxidant activity in plants growing under heavy metal stress," Polish Journal of Environmental Studies, vol. 15, no. 4, pp. 523-530, 2006.

[35] K. Yokota and I. Yamazaki, "Reaction of peroxidase with reduced nicotinamide-adenine dinucleotide and reduced nicotinamide-adenine dinucleotide phosphate," Biochimica et Biophysica Acta, vol. 105, no. 2, pp. 301-312, 1965.

[36] A. Holzenburg and N. S. Scrutton, Enzyme-Catalyzed Electron and Radical Transfer, vol. 35 of Subcellular Biochemistry, Springer, Berlin, Germany, 2000.

[37] I. M. Kolthoff and A. I. Medalia, “The reaction between ferrous iron and peroxides. I. Reaction with hydrogen peroxide in the absence of oxygen," Journal of the American Chemical Society, vol. 71, no. 11, pp. 3777-3783, 1949.

[38] M. R. Gunther, P. M. Hanna, R. P. Mason, and M. S. Cohen, "Hydroxyl radical formation from cuprous ion and hydrogen peroxide: A Spin-Trapping Study," Archives of Biochemistry and Biophysics, vol. 316, no. 1, pp. 515-522, 1995. 
[39] J. Cadet, T. Delatour, T. Douki et al., "Hydroxyl radicals and DNA base damage," Mutation Research/Fundamental and Molecular Mechanisms of Mutagenesis, vol. 424, no. 1-2, pp.9-21, 1999.

[40] A. Ayala, M. F. Muñoz, and S. Argüelles, "Lipid peroxidation: production, metabolism, and signaling mechanisms of malondialdehyde and 4-hydroxy-2-nonenal," Oxidative Medicine and Cellular Longevity, vol. 2014, Article ID 360438, 31 pages, 2014.

[41] J. M. C. Gutteridge, "The role of superoxide and hydroxyl radicals in phospholipid peroxidation catalysed by iron salts," FEBS Letters, vol. 150, no. 2, pp. 454-458, 1982.

[42] Y. Zhang, O. Marcillat, C. Giulivi, L. Ernster, and K. J. A. Davies, "The oxidative inactivation of mitochondrial electron transport chain components and ATPase," Journal of Biological Chemistry, vol. 265, no. 27, pp. 16330-16336, 1990.

[43] B. Chance, H. Sies, and A. Boveris, "Hydroperoxide metabolism in mammalian organs," Physiological Reviews, vol. 59, no. 3, pp. 527-605, 1979.

[44] J. Cadet and J. R. Wagner, "DNA base damage by reactive oxygen species, oxidizing agents, and UV radiation," Cold Spring Harbor Perspectives in Biology, vol. 5, no. 2, Article ID a012559, 2013.

[45] M. D. Evans, M. Dizdaroglu, and M. S. Cooke, "Oxidative DNA damage and disease: induction, repair and significance," Mutation Research/Reviews in Mutation Research, vol. 567, no. 1, pp. 1-61, 2004.

[46] C. R. Guest, "Dynamics of mismatched base Pairs in DNA," Biochemistry, vol. 30, no. 13, pp. 3271-3279, 1991.

[47] P. A. Jeggo and M. Löbrich, "DNA double-strand breaks: their cellular and clinical impact?" Oncogene, vol. 26, no. 56, pp. 77177719, 2007.

[48] K. W. Caldecott, "Single-strand break repair and genetic disease," Nature Reviews Genetics, vol. 9, no. 8, pp. 619-631, 2008.

[49] R. K. Singh and M. Krishna, "DNA strand breaks signal the induction of DNA double-strand break repair in Saccharomyces cerevisiae," Radiation Research, vol. 164, no. 6, pp. 781-790, 2005.

[50] J. E. Klaunig, L. M. Kamendulis, and B. A. Hocevar, "Oxidative stress and oxidative damage in carcinogenesis," Toxicologic Pathology, vol. 38, no. 1, pp. 96-109, 2010.

[51] J. H. J. Hoeijmakers, "DNA damage, aging, and cancer," The New England Journal of Medicine, vol. 361, no. 15, pp. 1475-1485, 2009.

[52] M. Toshiyuki and J. C. Reed, "Tumor suppressor p53 is a direct transcriptional activator of the human bax gene," Cell, vol. 80, no. 2, pp. 293-299, 1995.

[53] K. Rajalingam, R. Schreck, U. R. Rapp, and Š. Albert, "Ras oncogenes and their downstream targets," Biochimica et Biophysica Acta-Molecular Cell Research, vol. 1773, no. 8, pp. 1177-1195, 2007.

[54] S. Toyooka, T. Tsuda, and A. F. Gazdar, "The TP53 gene, tobacco exposure, and lung cancer," Human Mutation, vol. 21, no. 3, pp. 229-239, 2003.

[55] I. A. Prior, P. D. Lewis, and C. Mattos, "A comprehensive survey of ras mutations in cancer," Cancer Research, vol. 72, no. 10, pp. 2457-2467, 2012.

[56] G.-Y. Liou and P. Storz, "Reactive oxygen species in cancer," Free Radical Research, vol. 44, no. 5, pp. 479-496, 2010.

[57] C. Lennicke, J. Rahn, R. Lichtenfels, L. A. Wessjohann, and B. Seliger, "Hydrogen peroxide-production, fate and role in redox signaling of tumor cells," Cell Communication and Signaling, vol. 13, no. 1, article 39, 2015.
[58] A. Östman, C. Hellberg, and F. D. Böhmer, "Protein-tyrosine phosphatases and cancer," Nature Reviews Cancer, vol. 6, no. 4, pp. 307-320, 2006.

[59] M. Schieber and N. S. Chandel, "ROS function in redox signaling and oxidative stress," Current Biology, vol. 24, no. 10, pp. R453-R462, 2014.

[60] V. Gupta and K. S. Carroll, "Sulfenic acid chemistry, detection and cellular lifetime," Biochimica et Biophysica Acta-General Subjects, vol. 1840, no. 2, pp. 847-875, 2014.

[61] A. Pastore, G. Federici, E. Bertini, and F. Piemonte, "Analysis of glutathione: implication in redox and detoxification," Clinica Chimica Acta, vol. 333, no. 1-2, pp. 19-39, 2003.

[62] J. Duan, V. K. Kodali, M. J. Gaffrey et al., "Quantitative profiling of protein S-glutathionylation reveals redox-dependent regulation of macrophage function during nanoparticle-induced oxidative stress," ACS Nano, vol. 10, no. 1, pp. 524-538, 2016.

[63] L. A. Defelipe, E. Lanzarotti, D. Gauto, M. A. Marti, and A. G. Turjanski, "Protein topology determines cysteine oxidation fate: the case of sulfenyl amide formation among protein families," PLoS Computational Biology, vol. 11, no. 3, Article ID e1004051, 2015.

[64] K. J. Woycechowsky and R. T. Raines, "Native disulfide bond formation in proteins," Current Opinion in Chemical Biology, vol. 4, no. 5, pp. 533-539, 2000.

[65] H. S. Chung, S.-B. Wang, V. Venkatraman, C. I. Murray, and J. E. Van Eyk, "Cysteine oxidative posttranslational modifications: emerging regulation in the cardiovascular system," Circulation Research, vol. 112, no. 2, pp. 382-392, 2013.

[66] C. Klomsiri, P. A. Karplus, and L. B. Poole, "Cysteine-based redox switches in enzymes," Antioxidants \& Redox Signaling, vol. 14, no. 6, pp. 1065-1077, 2011.

[67] R. Rainwater, D. Parks, M. E. Anderson, P. Tegtmeyer, and K. Mann, "Role of cysteine residues in regulation of p53 function," Molecular and Cellular Biology, vol. 15, no. 7, pp. 3892-3903, 1995.

[68] M. Amir, K. Liu, E. Zhao, and M. J. Czaja, "Distinct functions of JNK and c-Jun in oxidant-induced hepatocyte death," Journal of Cellular Biochemistry, vol. 113, no. 10, pp. 3254-3265, 2012.

[69] H.-L. Hsieh, H.-H. Wang, C.-Y. Wu, and C.-M. Yang, "Reactive oxygen species-dependent $\mathrm{c}$-fos/activator protein 1 induction upregulates heme oxygenase-1 expression by bradykinin in brain astrocytes," Antioxidants \& Redox Signaling, vol. 13, no. 12, pp. 1829-1844, 2010.

[70] Y. Sun and L. W. Oberley, "Redox regulation of transcriptional activators," Free Radical Biology \& Medicine, vol. 21, no. 3, pp. 335-348, 1996.

[71] K. V. Tormos, E. Anso, R. B. Hamanaka et al., "Mitochondrial complex III ROS regulate adipocyte differentiation," Cell Metabolism, vol. 14, no. 4, pp. 537-544, 2011.

[72] W. Wang, Y. Zhang, W. Lu, and K. Liu, "Mitochondrial reactive oxygen species regulate adipocyte differentiation of mesenchymal stem cells in hematopoietic stress induced by arabinosylcytosine," PLoS ONE, vol. 10, no. 3, article e0120629, 2015.

[73] K. Bedard and K.-H. Krause, "The NOX family of ROSgenerating NADPH oxidases: physiology and pathophysiology," Physiological Reviews, vol. 87, no. 1, pp. 245-313, 2007.

[74] R. Harrison, "Structure and function of xanthine oxidoreductase: where are we now?" Free Radical Biology \& Medicine, vol. 33, no. 6, pp. 774-797, 2002.

[75] W. K. Alderton, C. E. Cooper, and R. G. Knowles, "Nitric oxide synthases: structure, function and inhibition," Biochemical Journal, vol. 357, no. 3, pp. 593-615, 2001. 
[76] B. S. van der Veen, M. P. de Winther, and P. Heeringa, "Myeloperoxidase: molecular mechanisms of action and their relevance to human health and disease," Antioxidants \& Redox Signaling, vol. 11, no. 11, pp. 2899-2937, 2009.

[77] K. Satoh, P. Nigro, and B. C. Berk, "Oxidative stress and vascular smooth muscle cell growth: a mechanistic linkage by cyclophilin A," Antioxidants \& Redox Signaling, vol. 12, no. 5, pp. 675-682, 2010.

[78] S. Godo, A. Sawada, H. Saito et al., "Disruption of physiological balance between nitric oxide and endothelium-dependent hyperpolarization impairs cardiovascular homeostasis in mice," Arteriosclerosis, Thrombosis, and Vascular Biology, vol. 36, no. 1, pp. 97-107, 2016.

[79] B. G. Vickrey, T. S. Rector, S. L. Wickstrom et al., "Occurrence of secondary ischemic events among persons with atherosclerotic vascular disease," Stroke, vol. 33, no. 4, pp. 901-906, 2002.

[80] R. K. Wadhera, D. L. Steen, I. Khan, R. P. Giugliano, and J. M. Foody, "A review of low-density lipoprotein cholesterol, treatment strategies, and its impact on cardiovascular disease morbidity and mortality," Journal of Clinical Lipidology, vol. 10, no. 3, pp. 472-489, 2016.

[81] S. Parthasarathy, A. Raghavamenon, M. O. Garelnabi, and N. Santanam, "Oxidized low-density lipoprotein," in Free Radicals and Antioxidant Protocols, R. M. Uppu, S. N. Murthy, W. A. Pryor, and N. L. Parinandi, Eds., vol. 610 of Methods in Molecular Biology, pp. 403-417, 2010.

[82] B. Fuhrman, A. Partoush, N. Volkova, and M. Aviram, "OxLDL induces monocyte-to-macrophage differentiation in vivo: possible role for the macrophage colony stimulating factor receptor (M-CSF-R)," Atherosclerosis, vol. 196, no. 2, pp. 598607, 2008.

[83] Z. Chi and A. J. Melendez, "Role of cell adhesion molecules and immune-cell migration in the initiation, onset and development of atherosclerosis," Cell Adhesion \& Migration, vol. 1, no. 4, pp. 171-175, 2007.

[84] A. Hoeben, B. Landuyt, M. S. Highley, H. Wildiers, A. T. Van Oosterom, and E. A. De Bruijn, "Vascular endothelial growth factor and angiogenesis," Pharmacological Reviews, vol. 56, no. 4, pp. 549-580, 2004.

[85] J. H. L. Yun Soo Bae, S. H. Choi, S. Kim, F. Almazan, J. L. Witztum, and Y. I. Miller, "Macrophages generate reactive oxygen species in response to minimally oxidized low-density lipoprotein toll-like recpetor 4 and speen tyrosine kinase-dependent activation of NADPH oxidase 2," Circulation Research, vol. 104, pp. 210-218, 2009.

[86] H. Itabe, T. Obama, and R. Kato, "The dynamics of oxidized LDL during atherogenesis," Journal of Lipids, vol. 2011, Article ID 418313, 9 pages, 2011.

[87] G. K. Kolluru, S. C. Bir, and C. G. Kevil, "Endothelial dysfunction and diabetes: effects on angiogenesis, vascular remodeling, and wound healing," International Journal of Vascular Medicine, vol. 2012, Article ID 918267, 30 pages, 2012.

[88] N. R. Madamanchi, A. Vendrov, and M. S. Runge, "Oxidative stress and vascular disease," Arteriosclerosis, Thrombosis, and Vascular Biology, vol. 25, no. 1, pp. 29-38, 2005.

[89] J. A. Ambrose, M. A. Tannenbaum, D. Alexopoulos et al., "Angiographic progression of coronary artery disease and the development of myocardial infarction," Journal of the American College of Cardiology, vol. 12, no. 1, pp. 56-62, 1988.

[90] J. F. Arenillas, "Intracranial atherosclerosis: current concepts," Stroke, vol. 42, no. 1, pp. S20-S23, 2011.
[91] A. R. Chade, A. Lerman, and L. O. Lerman, "Kidney in early atherosclerosis," Hypertension, vol. 45, no. 6, pp. 1042-1049, 2005.

[92] E. D. Freis, "Hypertension and atherosclerosis," The American Journal of Medicine, vol. 46, no. 5, pp. 735-740, 1969.

[93] P. J. Andrew and B. Mayer, "Enzymatic function of nitric oxide synthases," Cardiovascular Research, vol. 43, no. 3, pp. 521-531, 1999.

[94] U. Förstermann and T. Münzel, "Endothelial nitric oxide synthase in vascular disease: from marvel to menace," Circulation, vol. 113, no. 13, pp. 1708-1714, 2006.

[95] P. M. Kris-Etherton, A. H. Lichtenstein, B. V. Howard, D. Steinberg, and J. L. Witztum, "Antioxidant vitamin supplements and cardiovascular disease," Circulation, vol. 110, no. 5, pp. 637641, 2004.

[96] S. L. Nuttall, M. J. Kendall, and U. Martin, "Antioxidant therapy for the prevention of cardiovascular disease," Quarterly Journal of Medicine, vol. 92, no. 5, pp. 239-244, 1999.

[97] K.-T. Khaw, S. Bingham, A. Welch et al., "Relation between plasma ascorbic acid and mortality in men and women in EPICNorfolk prospective study: a prospective population study," The Lancet, vol. 357, no. 9257, pp. 657-663, 2001.

[98] C. R. Gale, C. N. Martyn, P. D. Winter, and C. Cooper, "Vitamin $\mathrm{C}$ and risk of death from stroke and coronary heart disease in cohort of elderly people," British Medical Journal, vol. 310, no. 6994, pp. 1563-1566, 1995.

[99] R. Collins, J. Armitage, S. Parish, P. Sleight, and R. Peto, "MRC/BHF Heart Protection Study of antioxidant vitamin supplementation in 20,536 high-risk individuals: a randomised placebo-controlled trial," The Lancet, vol. 360, no. 9326, pp. $23-$ 33, 2002.

[100] S.-K. Myung, W. Ju, B. Cho et al., "Efficacy of vitamin and antioxidant supplements in prevention of cardiovascular disease: systematic review and meta-analysis of randomised controlled trials," British Medical Journal, vol. 346, article F10, 2013.

[101] D. P. Vivekananthan, M. S. Penn, S. K. Sapp, A. Hsu, and E. J. Topol, "Use of antioxidant vitamins for the prevention of cardiovascular disease: meta-analysis of randomised trials," The Lancet, vol. 361, no. 9374, pp. 2017-2023, 2003.

[102] M. Boaz, S. Smetana, T. Weinstein et al., "Secondary prevention with antioxidants of cardiovascular disease in endstage renal disease (SPACE): randomised placebo-controlled trial," The Lancet, vol. 356, no. 9237, pp. 1213-1218, 2000.

[103] B. B. Aggarwal, C. Sundaram, S. Prasad, and R. Kannappan, "Tocotrienols, the vitamin E of the 21st century: its potential against cancer and other chronic diseases," Biochemical Pharmacology, vol. 80, no. 11, pp. 1613-1631, 2010.

[104] R. B.-F. Brigelius-Flohé and M. G. Traber, "Vitamin E: function and metabolism," The FASEB Journal, vol. 13, no. 10, pp. 1145$1155,1999$.

[105] M. J. Stampfer, C. H. Hennekens, J. E. Manson, G. A. Colditz, B. Rosner, and W. C. Willett, "Vitamin E consumption and the risk of coronary disease in women," The New England Journal of Medicine, vol. 328, no. 20, pp. 1444-1449, 1993.

[106] E. B. Rimm, M. J. Stampfer, A. Ascherio, E. Giovannucci, G. A. Colditz, and W. C. Willett, "Vitamin E consumption and the risk of coronary heart disease in men," The New England Journal of Medicine, vol. 328, no. 20, pp. 1450-1456, 1993.

[107] L. H. Kushi, A. R. Folsom, R. J. Prineas, P. J. Mink, Y. Wu, and R. M. Bostick, "Dietary antioxidant vitamins and death from coronary heart disease in postmenopausal women," The New England Journal of Medicine, vol. 334, no. 18, pp. 1156-1162, 1996. 
[108] K. G. Losonczy, T. B. Harris, and R. J. Havlik, "Vitamin E and vitamin $\mathrm{C}$ supplement use and risk of all-cause and coronary heart disease mortality in older persons: the Established Populations for Epidemiologic Studies of the Elderly," American Journal of Clinical Nutrition, vol. 64, no. 2, pp. 190-196, 1996.

[109] P. Di Mascio, S. Kaiser, and H. Sies, "Lycopene as the most efficient biological carotenoid singlet oxygen quencher," Archives of Biochemistry and Biophysics, vol. 274, no. 2, pp. 532-538, 1989.

[110] S. B. Nimse and D. Pal, "Free radicals, natural antioxidants, and their reaction mechanisms," RSC Advances, vol. 5, no. 35, pp. 27986-28006, 2015.

[111] S. B. Kritchevsky, “ $\beta$-carotene, carotenoids and the prevention of coronary heart disease," Journal of Nutrition, vol. 129, no. 1, pp. 5-8, 1999.

[112] S. Voutilainen, T. Nurmi, J. Mursu, and T. H. Rissanen, "Carotenoids and cardiovascular health," American Journal of Clinical Nutrition, vol. 83, no. 6, pp. 1265-1271, 2006.

[113] P. M. O'Connor and D. D. Gutterman, "Resurrecting hope for antioxidant treatment of cardiovascular disease: focus on mitochondria," Circulation Research, vol. 107, no. 1, pp. 9-11, 2010.

[114] E. D. Thomas, R. Storb, R. A. Clift et al., "Bone-marrow transplantation," The New England Journal of Medicine, vol. 292, no. 17, pp. 895-902, 1975.

[115] M. Edinger, P. Hoffmann, J. Ermann et al., "CD $4{ }^{+} \mathrm{CD} 25^{+}$regulatory $\mathrm{T}$ cells preserve graft-versus-tumor activity while inhibiting graft-versus-host disease after bone marrow transplantation," Nature Medicine, vol. 9, no. 9, pp. 1144-1150, 2003.

[116] B. Vaes, W. Van’t Hof, R. Deans, and J. Pinxteren, "Application of Multistem ${ }^{\circledR}$ allogeneic cells for immunomodulatory therapy: clinical progress and pre-clinical challenges in prophylaxis for graft versus host disease," Frontiers in Immunology, vol. 3, article 345, 2012.

[117] J. M. Ryan, F. P. Barry, J. M. Murphy, and B. P. Mahon, "Mesenchymal stem cells avoid allogeneic rejection," Journal of Inflammation, vol. 2, article 8, 2005.

[118] S. A. Jacobs, V. D. Roobrouck, C. M. Verfaillie, and S. W. Van Gool, "Immunological characteristics of human mesenchymal stem cells and multipotent adult progenitor cells," Immunology and Cell Biology, vol. 91, no. 1, pp. 32-39, 2013.

[119] A. D. Lander, J. Kimble, H. Clevers et al., "What does the concept of the stem cell niche really mean today?" BMC Biology, vol. 10, article 19, 2012.

[120] N. Urao and M. Ushio-Fukai, "Redox regulation of stem/progenitor cells and bone marrow niche," Free Radical Biology and Medicine, vol. 54, pp. 26-39, 2013.

[121] J. M. Ryu, H. J. Lee, Y. H. Jung et al., "Regulation of stem cell fate by ROS-mediated alteration of metabolism," International Journal of Stem Cells, vol. 8, no. 1, pp. 24-35, 2015.

[122] K. Lamping, "Endothelial progenitor cells: sowing the seeds for vascular repair," Circulation Research, vol. 100, no. 9, pp. 1243$1245,2007$.

[123] M. Hristov, W. Erl, and P. C. Weber, "Endothelial progenitor cells-mobilization, differentiation, and homing," Arteriosclerosis, Thrombosis, and Vascular Biology, vol. 23, no. 7, pp. 11851189, 2003.

[124] C. L. Bigarella, R. Liang, and S. Ghaffari, "Stem cells and the impact of ROS signaling," Development, vol. 141, no. 22, pp. 4206-4218, 2014.

[125] M. Visweswaran, S. Pohl, F. Arfuso et al., "Multi-lineage differentiation of mesenchymal stem cells-to Wnt, or not Wnt,"
International Journal of Biochemistry \& Cell Biology, vol. 68, pp. 139-147, 2015.

[126] F. Atashi, A. Modarressi, and M. S. Pepper, "The role of reactive oxygen species in mesenchymal stem cell adipogenic and osteogenic differentiation: a review," Stem Cells and Development, vol. 24, no. 10, pp. 1150-1163, 2015.

[127] M. O. Gaby Rittfeld, "Bone marrow-derived mesenchymal stem cell transplant survival in the injured rodent spinal cord," Journal of Bone Marrow Research, vol. 2, article 146, 2014.

[128] Q. Chen, P. Shou, C. Zheng et al., "Fate decision of mesenchymal stem cells: adipocytes or osteoblasts?" Cell Death \& Differentiation, vol. 23, no. 7, pp. 1128-1139, 2016.

[129] L. Shao, H. Li, S. K. Pazhanisamy, A. Meng, Y. Wang, and D. Zhou, "Reactive oxygen species and hematopoietic stem cell senescence," International Journal of Hematology, vol. 94, no. 1, pp. 24-32, 2011.

[130] M. L. Porto, B. P. Rodrigues, T. N. Menezes et al., "Reactive oxygen species contribute to dysfunction of bone marrow hematopoietic stem cells in aged C57BL/6 J mice," Journal of Biomedical Science, vol. 22, article 97, 2015.

[131] Y. Chen, R. Yang, P. Guo, and Z. Ju, "Gadd45a deletion aggravates hematopoietic stem cell dysfunction in ATM-deficient mice," Protein \& Cell, vol. 5, no. 1, pp. 80-89, 2014.

[132] A. D. D'Souza, I. A. Parish, D. S. Krause, S. M. Kaech, and G. S. Shadel, "Reducing mitochondrial ROS improves disease-related pathology in a mouse model of ataxia-telangiectasia," Molecular Therapy, vol. 21, no. 1, pp. 42-48, 2013.

[133] S. Yalcin, X. Zhang, J. P. Luciano et al., "Foxo3 is essential for the regulation of ataxia telangiectasia mutated and oxidative stressmediated homeostasis of hematopoietic stem cells," The Journal of Biological Chemistry, vol. 283, no. 37, pp. 25692-25705, 2008.

[134] Z. Tothova, R. Kollipara, B. J. Huntly et al., "FoxOs are critical mediators of hematopoietic stem cell resistance to physiologic oxidative stress," Cell, vol. 128, no. 2, pp. 325-339, 2007.

[135] A. Ludin, S. Gur-Cohen, K. Golan et al., "Reactive oxygen species regulate hematopoietic stem cell self-renewal, migration and development, as well as their bone marrow microenvironment," Antioxidants and Redox Signaling, vol. 21, no. 11, pp. 1605-1619, 2014.

[136] T. Suda, K. Takubo, and G. L. Semenza, "Metabolic regulation of hematopoietic stem cells in the hypoxic niche," Cell Stem Cell, vol. 9, no. 4, pp. 298-310, 2011.

[137] C. Chen, Y. Liu, R. Liu et al., "TSC-mTOR maintains quiescence and function of hematopoietic stem cells by repressing mitochondrial biogenesis and reactive oxygen species," Journal of Experimental Medicine, vol. 205, no. 10, pp. 2397-2408, 2008.

[138] C. R. Geest and P. J. Coffer, "MAPK signaling pathways in the regulation of hematopoiesis," Journal of Leukocyte Biology, vol. 86, no. 2, pp. 237-250, 2009.

[139] H. I. Kornblum, "Introduction to neural stem cells," Stroke, vol. 38, no. 2, pp. 810-816, 2007.

[140] C. Coste, V. Neirinckx, A. Gothot, S. Wislet, and B. Rogister, "Are neural crest stem cells the missing link between hematopoietic and neurogenic niches?" Frontiers in Cellular Neuroscience, vol. 17, no. 9, article 218, 2015.

[141] J. E. Le Belle, N. M. Orozco, A. A. Paucar et al., "Proliferative neural stem cells have high endogenous ROS levels that regulate self-renewal and neurogenesis in a PI3K/Akt-dependant manner," Cell Stem Cell, vol. 8, no. 1, pp. 59-71, 2011.

[142] L. Drowley, M. Okada, S. Beckman et al., "Cellular antioxidant levels influence muscle stem cell therapy," Molecular Therapy, vol. 18, no. 10, pp. 1865-1873, 2010. 
[143] S. Wisel, M. Khan, M. L. Kuppusamy et al., "Pharmacological preconditioning of mesenchymal stem cells with trimetazidine (1-[2,3,4-trimethoxybenzyl]piperazine) protects hypoxic cells against oxidative stress and enhances recovery of myocardial function in infarcted heart through $\mathrm{Bcl}-2$ expression," The Journal of Pharmacology and Experimental Therapeutics, vol. 329, no. 2, pp. 543-550, 2009.

[144] M. A. Fischbach, J. A. Bluestone, and W. A. Lim, "Cell-based therapeutics: the next pillar of medicine," Science Translational Medicine, vol. 5, no. 179, Article ID 179ps7, 2013.

[145] V. Lubrano, S. Baldi, D. Napoli, and V. Longo, "Beneficial effect of Lisosan G on cultured human microvascular endothelial cells exposed to oxidised low density lipoprotein," Indian Journal of Medical Research, vol. 136, no. 1, pp. 82-88, 2012.

[146] S. Frassinetti, M. Gabriele, L. Caltavuturo, V. Longo, and L. Pucci, "Antimutagenic and antioxidant activity of a selected lectin-free common bean (Phaseolus vulgaris L.) in two cellbased models," Plant Foods for Human Nutrition, vol. 70, no. 1, pp. 35-41, 2015.

[147] D. Lucchesi, R. Russo, M. Gabriele et al., "Grain and bean lysates improve function of endothelial progenitor cells from human peripheral blood: involvement of the endogenous antioxidant defenses," PLoS ONE, vol. 9, no. 10, article e109298, 2014.

[148] B.-Q. Wang, "Salvia miltiorrhiza chemical and pharmacological review of a medicinal plant," Journal of Medicinal Plants Research, vol. 4, no. 25, pp. 2813-2820, 2010.

[149] Y. Tang, A. Jacobi, C. Vater, X. Zou, and M. Stiehler, "Salvianolic acid B protects human endothelial progenitor cells against oxidative stress-mediated dysfunction by modulating Akt/mTOR/4EBP1, p38 MAPK/ATF2, and ERK1/2 signaling pathways," Biochemical Pharmacology, vol. 90, no. 1, pp. 34-49, 2014.

[150] S. L. M.-N. Xibong Wang and K.-H. Lee, "New development in the chemistry and biology of the bioactive constituents of tanshen," Medical Research Reviews, vol. 27, no. 1, pp. 133-148, 2006.

[151] A. O. Chizhov, A. Dell, H. R. Morris et al., "A study of fucoidan from the brown seaweed Chorda filum," Carbohydrate Research, vol. 320, no. 1-2, pp. 108-119, 1999.

[152] J.-B. Lee, A. Takeshita, K. Hayashi, and T. Hayashi, "Structures and antiviral activities of polysaccharides from Sargassum trichophyllum," Carbohydrate Polymers, vol. 86, no. 2, pp. 995999, 2011.

[153] H. Noda, H. Amano, K. Arashima, and K. Nisizawa, "Antitumor activity of marine algae," Hydrobiologia, vol. 204-205, no. 1, pp. 577-584, 1990.

[154] S.-K. Min, O.-C. Kwon, S. Lee, K.-H. Park, and J.-K. Kim, "An antithrombotic fucoidan, unlike heparin, does not prolong bleeding time in a murine arterial thrombosis model: a comparative study of undaria pinnatifida sporophylls and fucus vesiculosus," Phytotherapy Research, vol. 26, no. 5, pp. 752-757, 2012.

[155] H. Y. Park, M. H. Han, C. Park et al., "Anti-inflammatory effects of fucoidan through inhibition of NF- $\kappa$ B, MAPK and Akt activation in lipopolysaccharide-induced BV2 microglia cells," Food and Chemical Toxicology, vol. 49, no. 8, pp. 1745-1752, 2011.

[156] M. C. R. de Souza, C. T. Marques, C. M. G. Dore, F. R. F. Da Silva, H. A. O. Rocha, and E. L. Leite, "Antioxidant activities of sulfated polysaccharides from brown and red seaweeds," Journal of Applied Phycology, vol. 19, no. 2, pp. 153-160, 2007.

[157] B. Li, F. Lu, X. Wei, and R. Zhao, "Fucoidan: structure and bioactivity," Molecules, vol. 13, no. 8, pp. 1671-1695, 2008.
[158] F. Zemani, D. Benisvy, I. Galy-Fauroux et al., "Low-molecularweight fucoidan enhances the proangiogenic phenotype of endothelial progenitor cells," Biochemical Pharmacology, vol. 70, no. 8, pp. 1167-1175, 2005.

[159] J. H. Lee, S. H. Lee, S. H. Choi, T. Asahara, and S.-M. Kwon, "The sulfated polysaccharide fucoidan rescues senescence of endothelial colony-forming cells for ischemic repair," STEM CELLS, vol. 33, no. 6, pp. 1939-1951, 2015.

[160] S. N. El and S. Karakaya, "Olive tree (Olea europaea) leaves: potential beneficial effects on human health," Nutrition Reviews, vol. 67, no. 11, pp. 632-638, 2009.

[161] E. Speromi, M. C. Guerra, A. Minghetti et al., "Oleuropein evaluated in vitro and in vivo as an antioxidant," Phytotherapy Research, vol. 12, no. 1, pp. 598-5100, 1998.

[162] S. H. Omar, "Cardioprotective and neuroprotective roles of oleuropein in olive," Saudi Pharmaceutical Journal, vol. 18, no. 3, pp. 111-121, 2010.

[163] R. de la Puerta, V. R. Gutierrez, and J. R. S. Hoult, "Inhibition of leukocyte 5-lipoxygenase by phenolics from virgin olive oil," Biochemical Pharmacology, vol. 57, no. 4, pp. 445-449, 1999.

[164] S. H. Choi, H. B. Joo, S. J. Lee et al., "Oleuropein prevents angiotensin II-mediated: human vascular progenitor cell depletion," International Journal of Cardiology, vol. 181, pp. 160-165, 2015.

[165] S. Li, H. Y. Tan, N. Wang et al., "Substitutes for bear bile for the treatment of liver diseases: research progress and future perspective," Evidence-Based Complementary and Alternative Medicine, vol. 2016, Article ID 4305074, 10 pages, 2016.

[166] J. G. Cho, J. H. Lee, S. H. Hong et al., “Tauroursodeoxycholic acid, a bile acid, promotes blood vessel repair by recruiting vasculogenic progenitor cells," Stem Cells, vol. 33, no. 3, pp. 792805, 2014. 


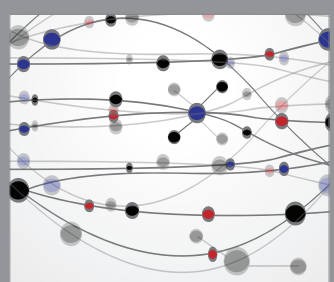

The Scientific World Journal
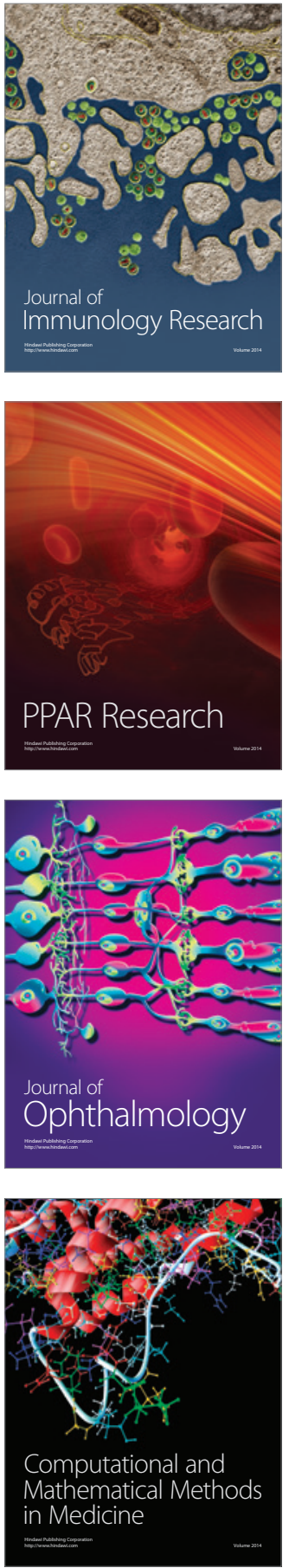

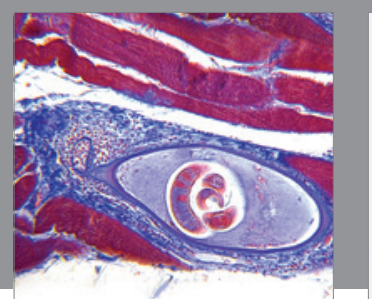

Gastroenterology Research and Practice

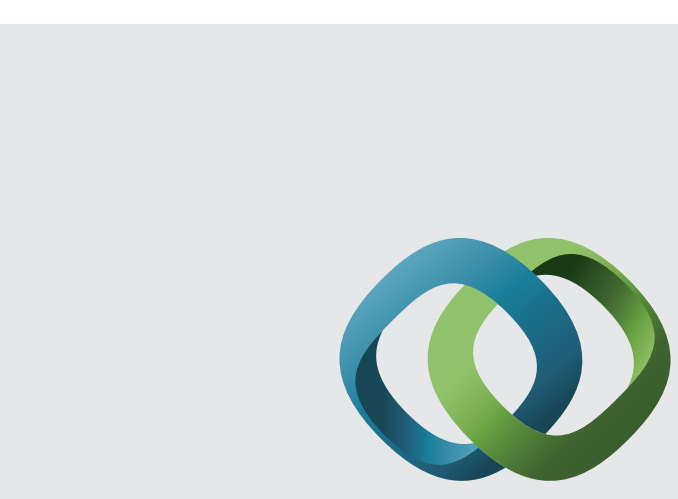

\section{Hindawi}

Submit your manuscripts at

http://www.hindawi.com
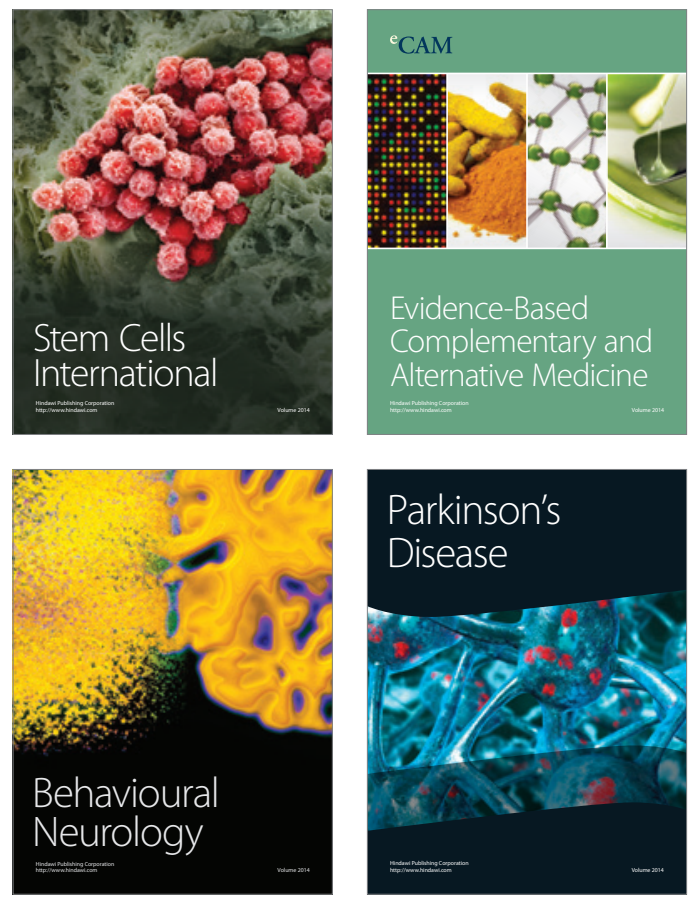
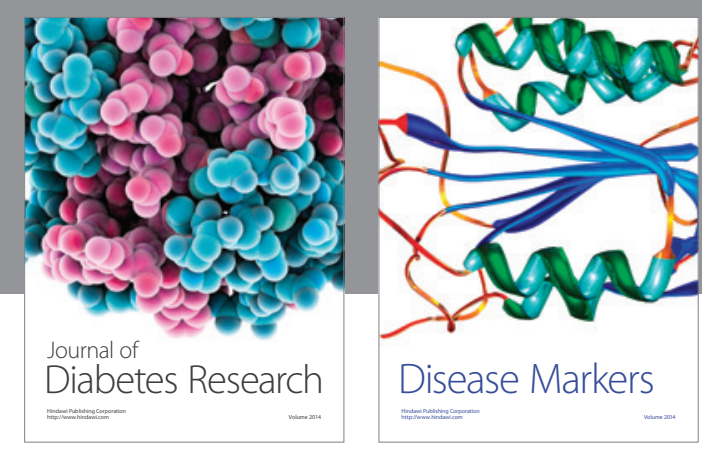

Disease Markers
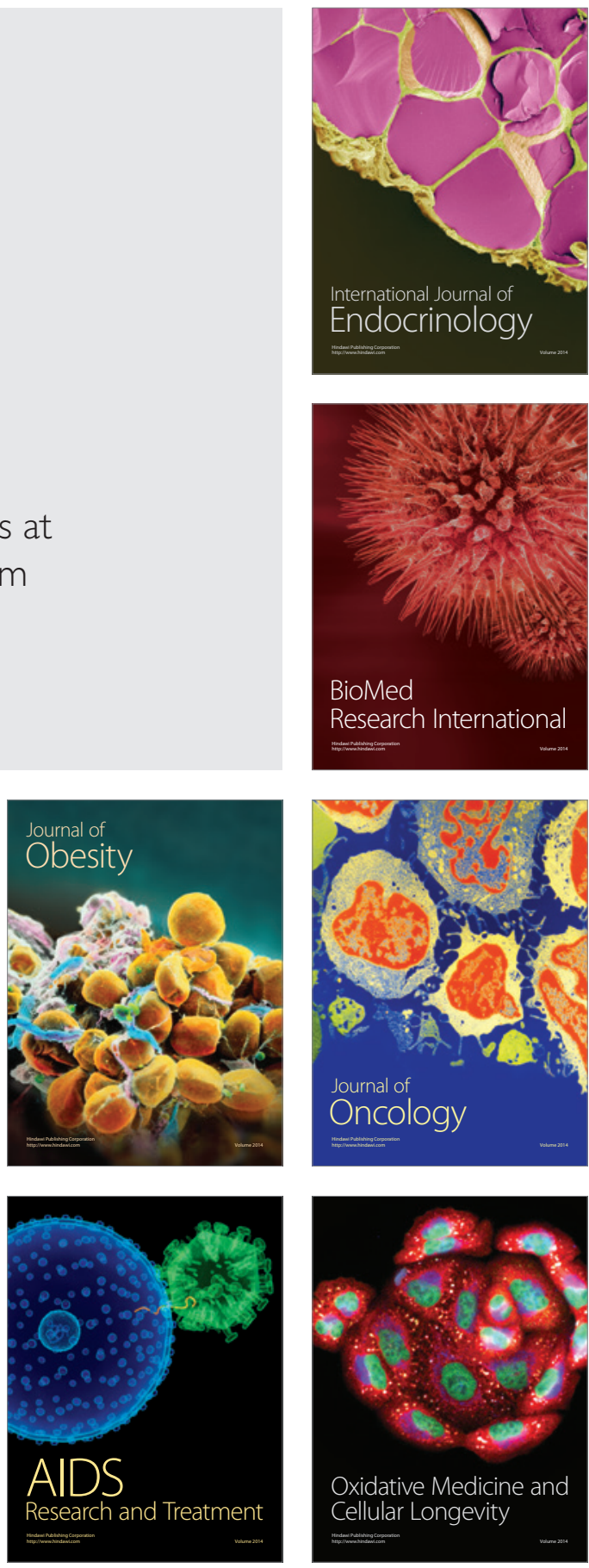